\title{
Interaction between stress hormones and phagocytic cells and its effect on the health status of dairy cows: A review
}

\author{
Mohanned Naif Alhussien (D) and Ajay Kumar Dang(D) \\ Lactation and Immuno-Physiology Laboratory, ICAR-National Dairy Research Institute, Karnal, Haryana, India. \\ Corresponding author: Mohanned Naif Alhussien, e-mail: mohannadalhussien@gmail.com \\ Co-author: AKD: rajadang@rediffmail.com \\ Received: 11-04-2020, Accepted: 22-07-2020, Published online: 10-09-2020
}

doi: www.doi.org/10.14202/vetworld.2020.1837-1848 How to cite this article: Alhussien MN, Dang AK (2020) Interaction between stress hormones and phagocytic cells and its effect on the health status of dairy cows: A review, Veterinary World, 13(9): 1837-1848.

\begin{abstract}
Dairy cows are exposed to various stressors during their production cycle that makes them more susceptible to various diseases. Phagocytes (neutrophils and macrophages) are important soldiers of the innate immune system. Neutrophils are the first responders to an inflammatory response and stress and kill pathogens by generating reactive oxygen species and by the release of various antimicrobial peptides, enzymes, neutrophil extracellular trap formation, etc. Macrophages, the other phagocytes, are also the cleanup crew for the innate immune system that removes debris, pathogens, and dead neutrophils later on after an inflammatory response. The neuroendocrine system along with phagocytes exhibits an immunomodulatory potential during stressful conditions. Neuroendocrine system directly affects the activity of phagocytes by communicating bidirectionally through shared receptors and messenger molecules such as hormones, neurotransmitters, or cytokines. Different immune cells may show variable responses to each hormone. Short time exposure to stress can be beneficial, but repeated or extended exposure to stress may be detrimental to the overall health and well-being of an animal. Although some stresses associated with farming practices in dairy cows are unavoidable, better understanding of the interactions occurring between various stress hormones and phagocytic cells can help to reduce stress, improve productivity and animal welfare. This review highlights the role played by various stress hormones in modulating phagocytic cell performance of dairy cattle under inflammatory conditions.
\end{abstract}

Keywords: dairy cattle, inflammatory diseases, leukocyte trafficking, macrophages, neutrophils.

\section{Introduction}

High-producing dairy cows have high metabolic demands around calving and during early lactation where the chances of developing health disorders are quite high [1-3]. This condition gets further aggravated when accompanied by extreme environmental conditions which provide an optimum condition for microbial growth and multiplications [4,5]. Adequate sensation and timely response of animals to these changes by neuroendocrine and immune system enable them to maintain their health and reproduction $[6,7]$. Animals experience various infections throughout their lifespans and they respond to these attacking pathogens by activating their highly sensitive receptor-based perception systems activating antimicrobial signaling cascades. For this, both polymorphonuclear leukocytes (PMNs) and macrophages (collectively known as phagocytic cells) have a highly sophisticated defense system, which enables them to precisely recognize pathogen molecules and clear them from the system [8-12]. The phagocytes (phagein means to eat and cyte stands for the cell) protect the body by

Copyright: Alhussien and Dang. Open Access. This article is distributed under the terms of the Creative Commons Attribution 4.0 International License (http://creativecommons.org/licenses/ by/4.0/), which permits unrestricted use, distribution, and reproduction in any medium, provided you give appropriate credit to the original author(s) and the source, provide a link to the Creative Commons license, and indicate if changes were made. The Creative Commons Public Domain Dedication waiver (http:// creativecommons.org/publicdomain/zero/1.0/) applies to the data made available in this article, unless otherwise stated. ingesting harmful foreign particles and have long been considered as essential cells for defense mechanism against invading pathogens. One hundred and fifteen years ago, Elie Metchnikoff discovered phagocytosis and suggested that the key to effective immunity was to "activate the phagocytes [13]." The activity of phagocytic cells, expression of surface adhesion molecules, as well as stress hormone receptors get modulated in response to environmental stress [14-16], physiological stress such as calving and early lactation $[14,17]$, and pathological stress such as mammary and uterine infections [18-23].

Stress is detrimental to health, and different stress hormones released during unfavorable conditions have multiple and different effects on the functionality and large-scale redistribution of immune cells $[15,16,24,25]$. These hormones are cortisol, catecholamine, growth hormones $(\mathrm{GH})$, prolactin (PRL), histamine, apelin, etc. Unlike glandular endocrine cells, phagocytic cells are considered to be both poly producers and poly receivers of hormones [26,27]. Since they are mobile cells, they can transport the stored hormone to the inflamed tissue contributing to the local synthesis and secretion of various hormones [28-33]. Although efforts have been made in the past to unravel the role of various hormones on phagocytes, understanding the molecular events by which stress hormones affect innate immunity is still unknown. Therefore, this review is an effort to address the latest breakthrough discovery related 
to the role of stress hormones in the modulation of phagocytic cells activity of dairy cows. Ultimately, a better understanding of the interactions between the stress hormones and the phagocytic cells can open up new therapeutic approaches and improve the well-being and sustainability of our dairy herds.

\section{Phagocytes Activation, Migration, and their Mode of Action}

The main phagocytic cells are macrophages in the tissues and PMNs in the bloodstream. Macrophages activation and PMNs migration process can be split up into several stages. It starts when activated macrophages release pro-inflammatory cytokines essentials for PMNs activation in the blood vessel, subsequent migration of PMNs to the inflamed site, and clearance of the pathogens [12]. Under normal physiological conditions, neutrophils circulate in the blood and survey for microbial-associated molecular patterns. Neutrophils are short-lived and are replaced every $24 \mathrm{~h}$. During the periods of stress, phagocytes get activated and express their secretory and cell membrane activity [11,34]. Many receptors, adhesion molecules, and cytokines are involved in the activation, migration, and fighting ability of phagocytes in response to an inflammatory process (Figure-1). The presence of a pathogen stimulates an inflammatory response in the host body through bacteria-derived inflammatory signals such as lipopolysaccharide (LPS), host-derived chemoattractants, and cytokines such as tumor necrosis factor (TNF)- $\alpha$ and interleukins [35]. These signals stimulate the endothelial cells to express adhesion molecules on the luminal surface, that is, the P-selectin (CD62P), E-selectin (CD62E), and endothelial intercellular adhesion molecules (ICAM-1 and ICAM-2). Thereafter, these adhesion molecules then get attached to the $\beta 2$ integrin $(C D 11 b /$ CD18) and L-selectin (CD62L) of neutrophils leading to tethering followed by rolling of neutrophils along the wall of the blood vessel $[12,35]$.

Binding of neutrophils to the endothelium forms a foundation for the beginning of transmigratory activity of neutrophils through the endothelial lining through interaction with its surface receptors (integrins) [36]. Eventually, matrix metalloproteinases, also known as collagenase, are released which help neutrophils to dissolve and penetrate the basement membrane and reach the site of inflammation. Moreover, the chemotactic gradient created by bacteria as well as host-derived chemokines facilitates the migration of neutrophils toward the site of inflammation. Phagocytes are also equipped with pattern recognition receptors which are capable of recognizing specific non-self-patterns present on foreign materials like the family of toll-like receptors (TLRs) [37]. Binding of phagocytic surface receptors to the complement

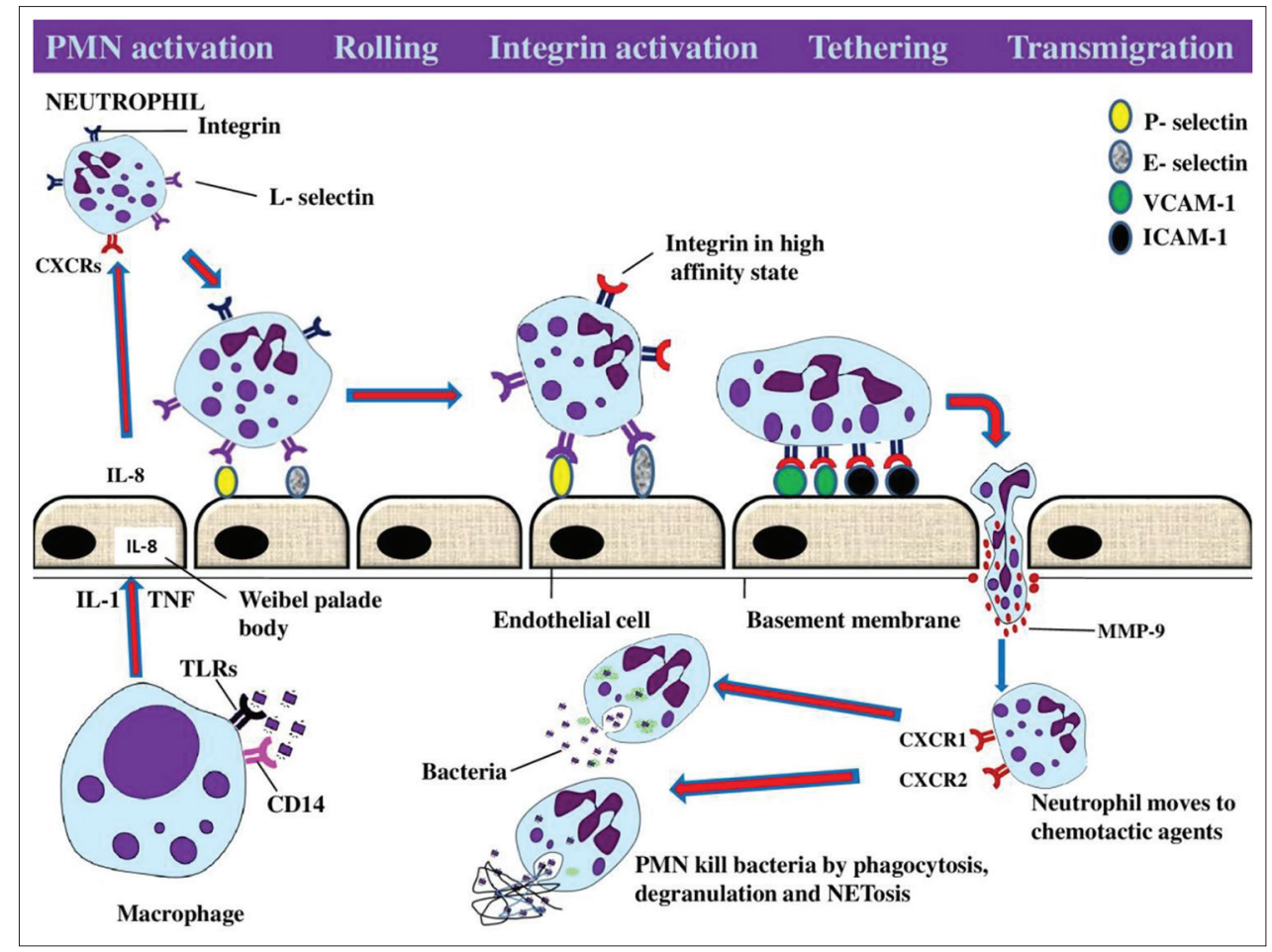

Figure-1: Diagrammatic representation of phagocytic cells activation and subsequent migration at the site of infection. Initially, macrophages in the tissue detect the presence of pathogens through CD-14 and toll-like receptors and secrete inflammatory cytokines such as IL-1 and tumor necrosis factor which further stimulate the release of interleukin (IL-8) from Weibel-Palade bodies as well as expression of both P-selectin and E-selectin on the surface of endothelial cells (ECs). IL- 8 binds to the chemokine receptors (CXCR1 and CXCR2) on the surface of polymorphonuclear leukocytes (PMNs) which causes PMNs activation. Activated neutrophils use L-selectin and integrin for slowing down and tethering to the ECs, respectively. Matrix metalloproteinases help in transmigration and chemokine receptors help PMNs to move toward the chemotactic gradients and perform their functions by various mechanisms. (Source: Mohanned Naif Alhussien and Ajay Kumar Dang). 
components and immunoglobulins results in further cell activation, and increased oxygen consumption and hexose monophosphate activity in a process called the "respiratory burst [35]." The intracellular granules of phagocytes contain different enzymes, that is, defensins, myeloperoxidase, elastase, and other enzymes which can efficiently kill a variety of invading organisms [12,35]. In addition, neutrophils can also trap and kill any foreign materials by releasing thread-like structures called neutrophil extracellular traps (NETs) [38,39]. Milk neutrophils have been reported to use NETs as a strategy in fighting against mastitis pathogens during mammary infections [40]. Once the neutrophils have fulfilled their physiological functions in the tissue, they undergo apoptosis and get cleared by the macrophages [35].

\section{Neuroendocrine Responses to Stress}

Stress in any form, physiological or pathological, causes the release of neuroendocrine signals from the brain. The main two neuroendocrine pathways activated in response to stress and control the immune system are the hypothalamic-pituitary-adrenal (HPA) axis and sympathetic nervous system (SNS) $[28,32]$. Stimulation of these two systems results in the release of glucocorticoids and catecholamines (epinephrine and norepinephrine), respectively (Figure-2). However, other neuroendocrine hormones (PRL, GH, histamine, and apelin) are also released following stress and involved in the regulation of phagocytic cells activity (Figure-2). Stress hormones serve as beacons that make the immune system ready for potential challenges perceived by the brain. Nevertheless, the homeostasis of this system may break down if the enhanced immune response is dysregulated after long activation, as seen during chronic stress $[32,33,41,42]$.

\section{Role of HPA Axis in Innate Immunity}

Hypothalamus of an animal receives and monitors information from the environment and coordinates it through various nerves and hormones. For optimum immunological response, a complex interaction occurs between the HPA axis and various constituents of the immune system. The brain regulates the immune system through activation of the HPA axis. On stimulation of this axis, corticotropin-releasing hormone is secreted from the paraventricular nucleus of the hypothalamus (Figure-3). This causes secretion of adrenocorticotropic hormone from the anterior pituitary into the circulation which further induces the adrenal glands to synthesize and secrete glucocorticoids [43]. Cortisol is a well-known marker for physiological stress and cattle with higher temperament scores exhibit greater cortisol concentration in their blood [44]. Cortisol has been reported as a stress marker in the milk of dairy cows [16,45]. Brown and Vosloo [46] demonstrated that intensification of dairy farming practices has increased the plasma cortisol

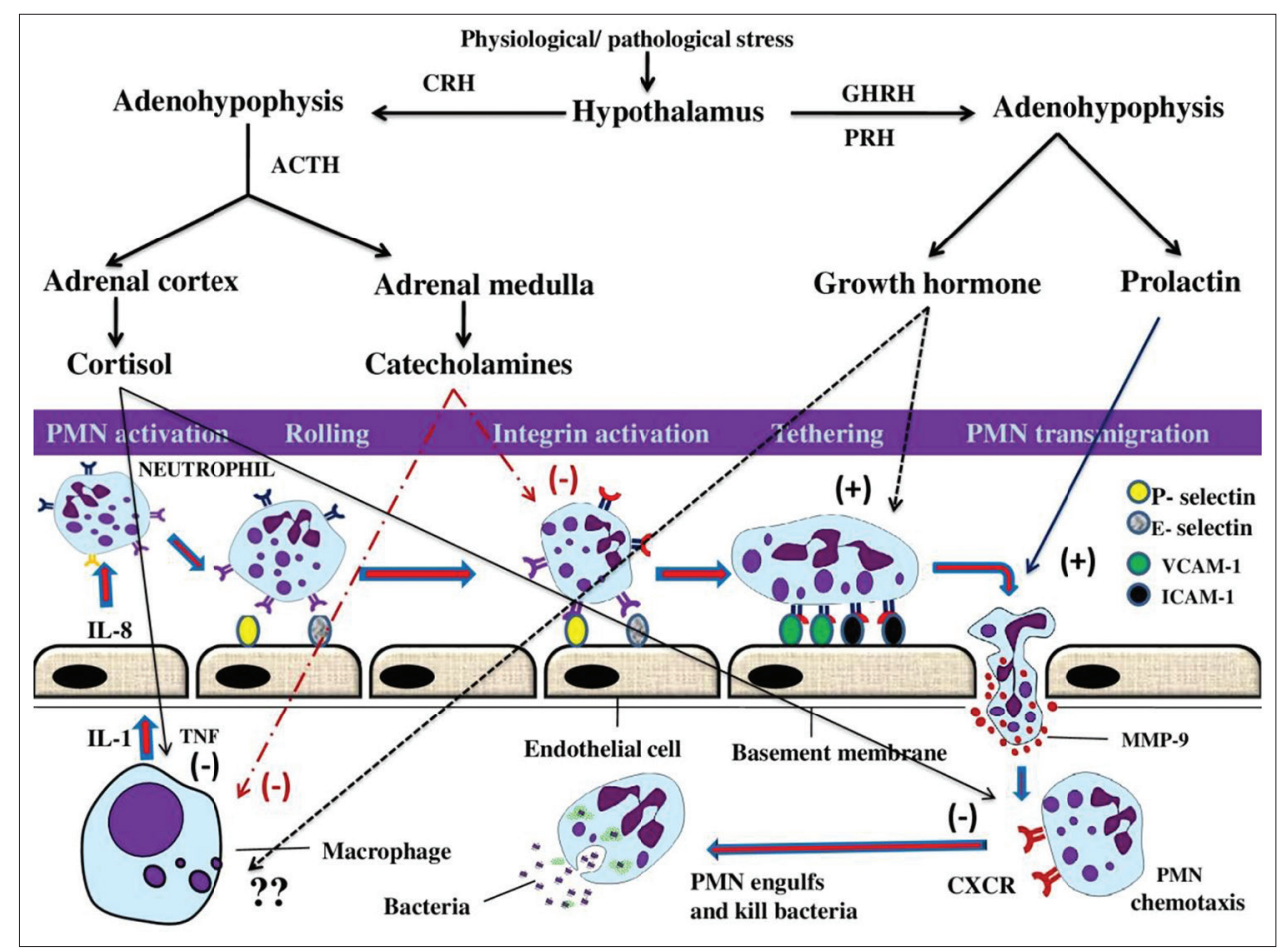

Figure-2: Stress modulation of the hormonal profile by the central nervous system. On experiencing an adverse stimulus (stressor), the hypothalamic-pituitary-adrenal axis and the sympathetic nervous system are activated resulting in the release of glucocorticoids and catecholamines, which can modulate and suppress various receptors and adhesion molecules involved in the activity of phagocytic cells. Furthermore, the pituitary hormones (prolactin and growth hormone) are also released which, however, enhance phagocytic cells activity. GHRH: Growth hormone-releasing hormone; PRH: Prolactinreleasing hormone; $\mathrm{CRH}$ : Corticotropin-releasing hormone; ACTH: Adrenocorticotropic hormone. Negative $(-)$ sign indicates an inhibitory effect, while positive $(+)$ sign indicates a stimulatory effect. (Source: Mohanned Naif Alhussien and Ajay Kumar Dang). 


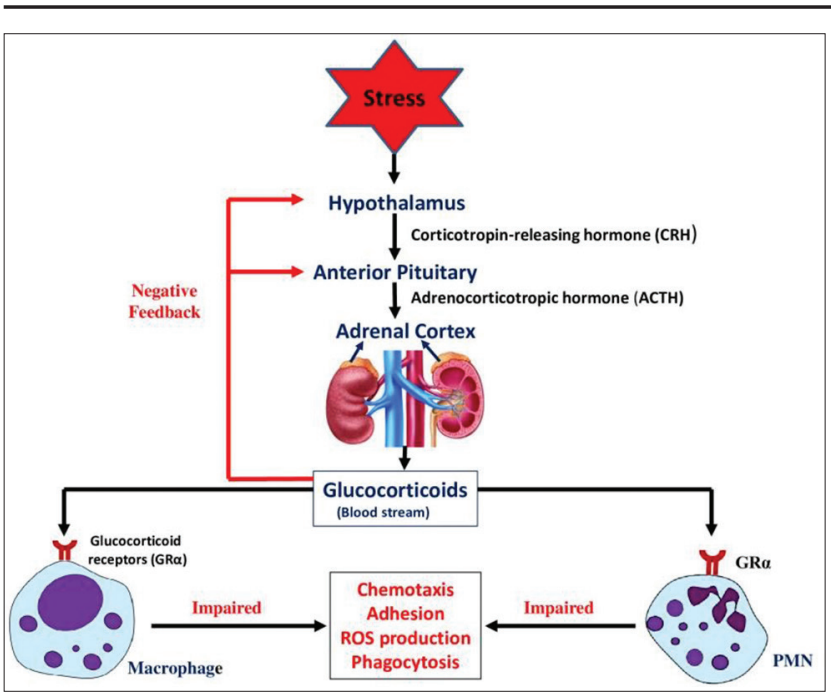

Figure-3: Diagrammatic representation of activation of the hypothalamic-pituitary-adrenal axis during stress/ inflammation and its subsequent effects on the activity of phagocytes. (Source: Mohanned Naif Alhussien and Ajay Kumar Dang).

levels in dairy animals. Although some of these practices are unavoidable, improving farming methods can lower the cortisol levels, increase the welfare and efficiency of cattle production.

Both PMNs and macrophages exhibit relatively abundant levels of glucocorticoid receptors in their cytoplasm and, through these receptors, the glucocorticoids tend to exert multiple effects on these cells (Figure-3). Studies have demonstrated that phagocytic activity of neutrophils gets diminished with a concomitant increase of plasma cortisol in the blood and milk of both parturient and mastitis cows [17,47,48]. A dramatic impairment in random migration, adhesion, and reactive oxygen species (ROS) production of blood PMNs has been observed during the $1^{\text {st }}$ week after parturition and during mammary infection in association with plasma cortisol elevation [41].

A linear relationship (positively correlated) was observed between cortisol concentration and expression of both chemokine receptors (CXCR1 and CXCR2) on PMNs of parturient and mastitis [17]. As discussed earlier, effective recruitment of phagocytes to the site of infection requires adhesion molecules, including the selectin and $\beta_{2}$ integrin families. Selectin (CD-62L) slows down the phagocytic cells and allows them to roll along vascular endothelial cells, while integrin (CD-11b) mediates tethering of PMNs to the endothelial cells. A linear relationship was also observed between cortisol concentration and the expression of integrin on both blood and milk PMNs during stressful conditions (mastitis and parturition), indicating more transmigration efficiency of neutrophils to the site of inflammation under such circumstances $[17,48]$. An increase in the plasma cortisol hormone has been recorded during extreme weather conditions $[49,50]$, which, in turn, caused immune disturbance, higher inflammatory response and decreases phagocytic activity of neutrophils during summer season [14-16,44]. Even the ability of neutrophils to detect invading pathogens is decreased as reflected by the lower expression of the TLRs on the surface of neutrophils during this period. Alhussien and Dang [16] observed higher milk cortisol concentrations in association with increased expression of heat shock proteins and CD molecules in neutrophils during heat stress in Indian native breeds of cattle.

Macrophages, through antigen presentation, act as a bridge linking innate and acquired immunity. They activate both $\mathrm{T}$ and $\mathrm{B}$ lymphocyte, enabling them to secrete cytokines, exert cytotoxic, suppressor, and memory functions [51]. As observed in PMNs, the activity of the macrophages also gets suppressed under the influence of glucocorticoids. Even administration of dexamethasone (a potent glucocorticoid) to dairy calves reduces the mRNA expression of TLRs and acute-phase cytokine on macrophages [52]. Macrophages are the prominent leukocyte in the milk of healthy animals but get highly outnumbered by PMN during mammary inflammation [48]. Mukherjee et al. [53] studied the effect of plasma cortisol on the activity of milk macrophage during different stages of lactation cycle. The highest phagocytic index (PI) of milk phagocytes was observed at calving and early and mid-stage of lactation which was positively correlated with plasma cortisol levels. However, during the late stage of lactation, an inverse relationship was observed between PI and plasma cortisol levels.

Recently, the anti-inflammatory effects of cortisol and the molecular mechanisms that mediate its action have been reported in ruminants. Dong et al. [42] demonstrated that high cortisol concentrations attenuate LPS-induced inflammatory responses in the RAW264.7 macrophage cell line by regulating the nuclear factor-kappa $\mathrm{B}$ (NF- $\mathrm{\kappa B})$ and mitogen-activated protein kinases (MAPK) signaling pathways. Cui et al. [54] demonstrated a two-side effect of cortisol in bovine endometrial epithelial cells (BEECs) stimulated with LPS, heat-killed Escherichia coli or live E. coli. They found that cortisol had anti-inflammatory effects on LPS- or heat-killed E. coli-stimulated BEEC, but displayed pro-inflammatory action on live E. coli-induced BEEC. Cui et al. [55] reported that cortisol impairs E. coli-induced endometrial inflammatory response through NF- $\mathrm{kB}$ and MAPK pathways in postpartum goats.

\section{The Role of SNS During Stress/Inflammation}

The SNS is mainly involved in the stimulation of fight or flight response to maintain homeostasis in the body. Activation of the SNS results in secretion of acetylcholine from the pre-ganglionic sympathetic fibers in the adrenal medulla. This induces the secretion of epinephrine into the systemic blood supply. Norepinephrine (a member of catecholamine family) is released from the nerve terminals in the vicinity of immune cells. Catecholamine concentrations are 
elevated in the blood of dairy cattle during stressful conditions [56]. The majority of immune cells (PMNs, macrophages, $\mathrm{T}$ and $\mathrm{B}$ lymphocytes, and NK cells) express $\beta 2$-adrenergic receptors on their surface. Excitation of the SNS causes the release of catecholamine into the circulation, which exerts their effects on immune cells that express adrenergic receptors on their surface [57]. These effects cause changes in immune cellular trafficking, proliferation, antibody production, and cytokine secretion and activity $[58,59]$.

In bovine PMNs, the $\beta 2$-adrenergic receptor signaling pathway is similar to that described in other species as well as the potential for an inflammatory stimulus to alter its function [60]. In physiologically stressed cows, high levels of blood catecholamine were involved in the impairment of CD-11b-mediated PMNs functions [61]. Moreover, epinephrine has been reported to modulate the trafficking of phagocytes, regulate cytokine secretion, and change host-pathogen interactions by altering microbial growth [32,62-64].

Macrophages not only respond to catecholamines, but they can also produce them as well. Activation of both $\left(\alpha_{1}-\mathrm{AR}\right.$ and $\left.\beta_{2}-\mathrm{AR}\right)$ suppresses the production of ROS in bovine alveolar macrophage [65]. During periods of immune system activation, bovine macrophages are involved in modulating catecholamine secretion from the adrenal chromaffin cell of adrenal medulla through releasing prostaglandin E2 and other chemical signals [66]. Glucocorticoid and catecholamine have combined effects on monocyte/macrophage and dendritic cells to inhibit the secretion of various pro-inflammatory cytokines and the acute-phase proteins while promoting the production of T-helper 2 humoral related cytokines [67,68]. Reiske et al. [59] studied the effects of in vitro treatment of porcine peripheral blood mononuclear cells with cortisol, adrenaline, or noradrenaline at increasing concentrations resembling low to high stress conditions. They reported that cortisol caused a decrease in the number of TNF- $\alpha$-producing cells and the mitogen-induced lymphocyte proliferation. However, catecholamines increased proliferation while exerting suppressive effects on the number of cytokine producers.

\section{Lactogenic Hormones During Infection and Immunity}

The lactogenic hormones are secreted by the anterior pituitary and stimulate mammogenesis and lactogenesis in the females. Both PRL and GH are necessary for the transition of the mammary gland from a proliferative to a lactating state. Indeed, they have been associated with structural and functional changes during the dry period and onset of lactation (period of mammary stress) in dairy cattle. Interestingly, these changes and lactogenic hormones elevation have been related to the periods of the highest incidence of infections $[69,70]$.

\section{PRL}

PRL, a protein hormone is synthesized and secreted from particular cells of the anterior pituitary gland, named lactotrophs. Several cells of the immune system such as macrophages, NK cells, and lymphocytes are considered as important sources for PRL synthesis $[26,71,72]$. In addition to its role in lactation, PRL has been shown to have significant involvement in immune functions, playing an important role in signaling between immune and neuroendocrine systems [26,27]. During infection and inflammation, PRL plays a critical role in maintaining the immune system homeostasis [26].

PRL triggers the pro-inflammatory immune response and PRL within physiologically achievable concentrations mediates PMNs migration of dairy cows [73]. Moreover, PRL induces phagocytosis of different microorganisms in both phagocytic (macrophages, PMNs) and non-phagocytic (epithelial) cells. In response, these cells produce pro-inflammatory cytokines and nitric oxide (NO), necessary for leukocyte recruitment to the site of infection. ROS and NO production in mice treated with PRL have reduced mortality and increased the phagocytic activity of macrophages in them [74]. However, PRL does not modify NO production in bovine macrophages infected with Mycobacterium avium subspecies paratuberculosis (M. avium ss. paratuberculosis). PRL can suppress the ability of bovine monocytes to control the intracellular growth of $M$. avium ss. paratuberculosis in vitro. Moreover, fluctuations in the levels of GH and PRL during parturition and lactation might make bovine mononuclear phagocytes more susceptible for the intracellular growth of $M$. avium ss. This phenomenon might be the main cause for the incidence of Johne's disease in dairy cattle [75].

Gutiérrez-Barroso et al. [76] have demonstrated that PRL in vitro together with Staphylococcus aureus downregulated mRNA expression of $\beta$-defensin and interleukin-1 $\beta$ as well as NO production in bovine mammary epithelial cells. These observations imply that PRL can inhibit host innate immune response elements during infection. Boutet et al. [73] reported no difference in the circulating levels of plasma PRL between healthy and mastitis-affected cows. However, milk PRL concentration increased in chronic mastitis-affected quarters and had a positive correlation with somatic cell count as well as the number of PMNs migrated to the milk. PRL is also reported to stimulate an inflammatory response in bovine mammary epithelial cells through NF-kB activation as well as cell adhesion expression, which results in more PMNs trafficking to the infected site during chronic mastitis [73].

Dairy steers during long-day photoperiods had higher levels of circulating PRL but reduced expression of PRL receptor on peripheral blood mononuclear cells compared to those exposed to short-day 
photoperiod [77]. Neutrophils isolated from cows assigned to a short-day photoperiod during the dry period had higher cellular trafficking toward various chemoattractants, while their lymphocytes showed enhanced cellular proliferation [78]. The highest phagocytic activity and PI of milk PMNs have been observed during mid-lactation while the lowest phagocytic activity and index seen during early lactation [14]. Similarly, lactation stage-specific effect of PRL on the mammary immunity has also been observed [53]. This is because PRL and other pituitary hormones are suggested to act as stress adaptation molecules essential for maintaining the homeostasis of mammary gland immunity throughout the lactation cycle. The inhibition of PRL has been reported as a promising strategy for reducing metabolic and acute nutritional stress during the postpartum period without compromising the overall productivity of dairy animals. Moreover, an improvement in some aspects of immune system has been associated with the inhibition of PRL during this period [70,79].

Research carried out on PRL over the recent years indicates that it functions as a survival factor, promotes proliferation, and inhibits apoptosis. These critical functions are important to maintain the desired number of immune cells in physiological conditions and also to enhance immune tolerance. Abnormal synthesis and secretion of PRL can disturb homeostasis of the immune system and subsequently promote autoreactivity or aggravation of the clinical condition in autoimmune diseases.

GH

$\mathrm{GH}$, also known as somatotropin, is another peptide hormone secreted by somatotropic cells of the anterior pituitary (Figure-4). Secretion of GH in the pituitary is regulated by two peptides, GH-releasing hormone and GH-inhibiting hormone (somatostatin) secreted from the hypothalamus (Figure-4). GH secretion from the pituitary is predominantly determined by the balance of these two peptides, which, in turn, is affected by the physiological/pathological status of the animal. Apart from the development of the mammary gland (ductal morphogenesis), milk synthesis, and metabolic regulation of periparturient dairy cows, it can also exert a direct effect on all major immune cell types and participate in the development and maintenance of both innate and adaptive immunity [80]. This hormone stimulates the production of insulin-like growth factor (IGF-1), which also has been found to be involved in the development of immune responses such as T-cell proliferation and activation, chemotaxis, apoptosis, and natural killer cell cytotoxicity $[81,82]$.

Somatotropin and IGF-1 are thought to be involved in several immune functions [83], and actions of bovine somatotropin (bST) can either be direct or indirectly mediated through IGF-1. An increased number of circulating leukocytes, band PMNs, and respiratory burst activity in cows treated with bST after calving have been reported [84]. No effect was observed in vitro as well as in vivo on phagocytosis and killing of $E$. coli by circulating PMN or on cytochrome c reduction [83]. However, an increase in the PMNs production of ROS after in vivo administration of bST has been reported in healthy cows [85]. bST does not affect chemotaxis and the expression of adhesion receptors of circulating PMNs during Streptococcus uberis mastitis, which is in contrast with coliform mastitis. Nevertheless, the absence of such

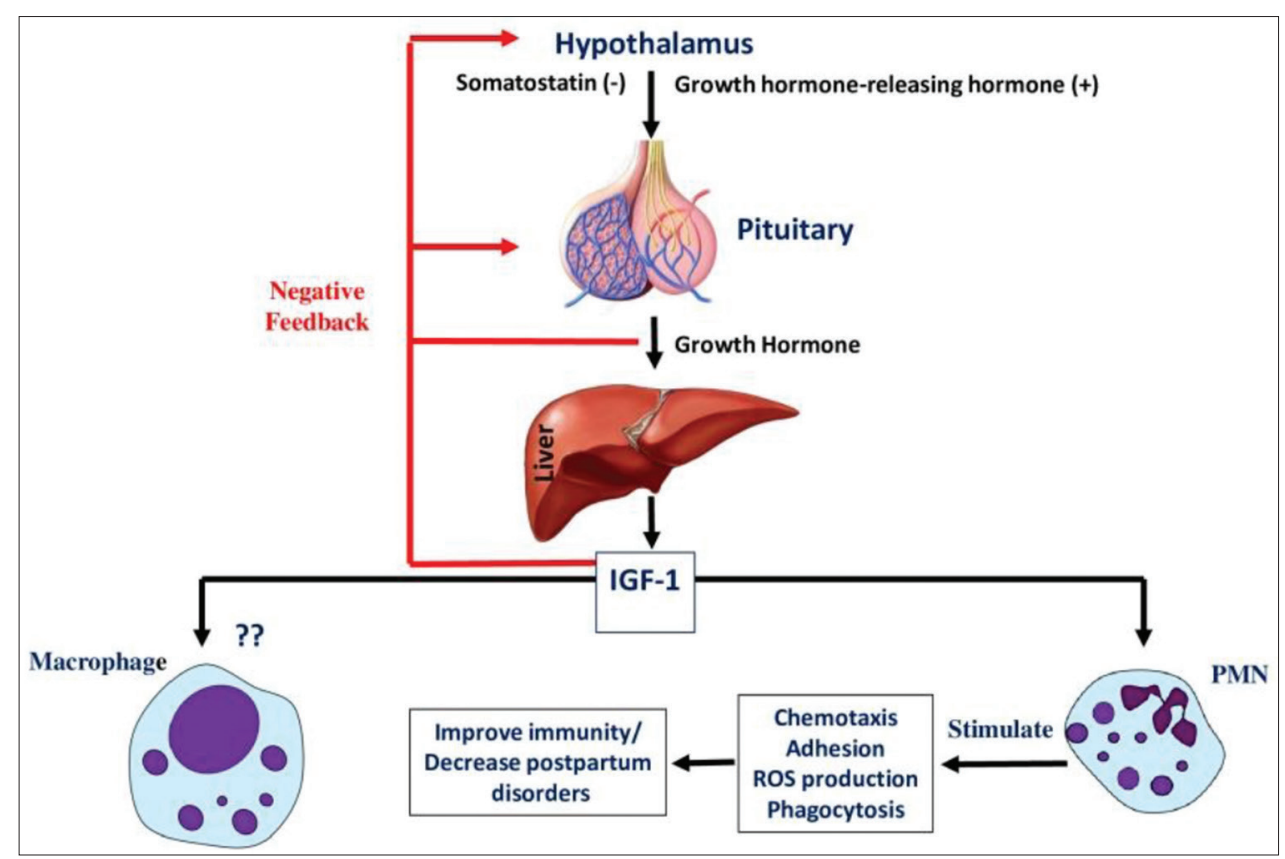

Figure-4: Diagrammatic representation of neuroendocrine activation of the growth hormone axis and its subsequent effects on the activity of phagocytes. IGF-1: Insulin-like growth factor 1 . Negative $(-)$ sign indicates an inhibitory effect while positive (+) sign indicates a stimulatory effect. (Source: Mohanned Naif Alhussien and Ajay Kumar Dang). 
effects is not essential for the outcome of $S$. uberis infection because the removal of $S$. uberis from the mammary gland is mainly dependent on macrophages rather than PMNs [86].

The activity of phagocytic cells from cows diagnosed with metritis was reduced during the prepartum period [87]. The ability of PMNs to perform phagocytosis and oxidative burst increased during the prepartum period in recombinant bST (rbST125) treated cows [88]. Treatment of cows with $142.8 \mathrm{mg}$ of rbST during the transition period did not affect metritis incidence but reduced the overall incidence of periparturient diseases [89]. However, the incidence of metritis and retained fetal membranes was decreased considerably in rbST 125 treated cows, which may be due to the enhancement of PMNs and macrophages activity by rbST $[88,90]$.

In the human model, $\mathrm{GH}$ reported modulating the acute-phase response by increasing IGF-1 and decreasing interleukin-1 expression, which subsequently causes a decrease in type 1 acute-phase proteins and increases in the constitutive hepatic proteins [91]. Metritis cows treated with rbST had a considerable decrease in the TNF- $\alpha$ concentrations [88]. The great role played by $\mathrm{GH}$ in enhancing immunity by acting directly or indirectly on immune cells, suggests that rbST treatment during transition period might be quite beneficial. Administration of somatotropin in transition cows could be used as a prepartum strategy to increase IGF-1 concentrations, improve immune function, and decrease postpartum disorders.

\section{Histamine}

Histamine is an organic nitrogenous compound produced by histaminergic neurons located in the hypothalamus or released by mast cells, basophils, platelets, and enterochromaffin-like cells. Histamine mediates its effects by four types of receptors ( $\mathrm{H} 1$, H2, H3, and H4), which belong to the GPCRs family. Depending on the histaminergic receptor stimulated, histamine can either suppress or stimulate inflammatory reactions [92].

Many reports have found an essential and direct role for histamine in the regulation of PMNs dominant inflammatory reactions [93,94]. H4R can be strongly used as a novel target for the pharmacological $\bmod u$ lation of histamine-transferred immune signals [95]. Despite the fact that histamine is predominantly preformed and stored in mast cells and basophils, recent evidence suggested that PMNs can also synthesis and release histamine during the inflammatory process. Smuda et al. [93] reported that bone marrow-derived PMNs when stimulated with a range of TLR agonists, secreted histamine in response to LPSs. LPS-stimulated histamine release was also enhanced by coculture with granulocyte macrophage colony-stimulating factor. In equine, it has been observed that high concentrations of histamine in vitro stimulated PMNs to produce ROS through histamine
H1 receptors and the nicotinamide adenine dinucleotide phosphate oxidase pathway [96].

In bovines, Anderson et al. [97] identified the presence of histamine receptor on the bovine leukocytes, mainly the lymphocytes. The in vitro effects of histamine on the chemiluminescence response of bovine PMNs were determined [98] and the addition of histamine was found to suppress the chemiluminescence response of PMNs significantly. This suppression was mediated by the continuous presence of histamine in the culture media. Hydrogen peroxide generated chemiluminescence was similarly suppressed due to high histamine concentrations. Moreover, histamine has a pharmacological role in the control of the oxidative burst reaction of bovine PMNs [98]. The presence of histamine receptors on bovine peripheral blood lymphocytes (PBL) was screened [99], and it was found that bovine PBLs have both $\mathrm{H} 1$ and $\mathrm{H} 2$ receptors on their surfaces. Moreover, histamine-induced suppression of PBL mitogenesis was mediated only by $\mathrm{H} 2$ receptors and not by $\mathrm{H} 1$ receptors.

Histamine also plays an important role in normal ovulation, blastocyst implantation, placental blood flow regulation, lactation as well as regulating myometrial activity in response to allergic or infectious stimuli, and the normal parturition process $[100,101]$. Pregnancy-dependent alterations in histamine concentrations in blood plasma and reproductive tissues have been documented in bovine [102]. Accumulating findings suggest that myometrial cells express histaminergic receptors and cause uterine contraction and relaxation through $\mathrm{H} 1$ receptors and $\mathrm{H} 2$ receptors, respectively $[100,103]$. Aberrant uterine contraction may lead to certain pathological states such as preterm labor, dysfunctional labor, and powerful contractions at term leading to fetal hypoxia and distress. H1R was reported in buffalo myometrium and found to have an important role in regulating myometrial contractility during normal and pathological states [104]. Wang et al. [105] demonstrated that high expression of H2R and low expression of H1R in the endometrial tissue impaired the inflammatory immune response and prevented excessive uterine tissue damage in metritis cows. Sun et al. [106] demonstrated that histamine increased the mRNA expressions and concentrations of inflammatory cytokines, including TNF- $\alpha$, IL-6, and IL-1 $\beta$, thereby inducing the inflammatory response of bovine rumen epithelial cells through the NF- $\mathrm{KB}$ pathway. Chang et al. [107] reported that histamine activates the inflammatory immune response and impairs casein synthesis in mammary gland of dairy cows during subacute ruminal acidosis.

Although histamine is a small molecule of only 17 atoms, it is considered as one of the most important mediators of inflammation and immune reaction. However, its role in the activity of phagocytic cells during inflammatory conditions is still in its infancy. Identifying histamine roles in bovine reproduction and under normal and inflammatory conditions can help 
us to target this molecule for some other therapeutic purposes in the future.

\section{Apelin}

Apelin is a novel peptide, and the endogenous ligand for the G protein-coupled APJ receptor, an angiotensin-1-like receptor. It has also been classified as one of the recently discovered stress hormones, which was first isolated from the bovine stomach $[108,109]$. The physiologically active form of apelin is thought to be apelin-36. Apelin and its receptor APJ play a role in the HPA axis responses to various acute stressors [110]. A role for apelin in the regulation of the HPA axis responses to stress is supported through central administration of (Pyr1) apelin-13, which increases the expression of c-fos, a key indicator of neuronal activity, in the paraventricular nucleus [111]. Using APJ knockout mice, APJ has been shown to play a regulatory role in the modulation of the HPA axis responses to short-lasting stressors such as LPS infection (an immune stressor) and insulin-induced hypoglycemia (a metabolic stressor) [110].

Biologically active apelin and its mRNA have been shown to increase during pregnancy and lactation in the mammary gland of rats and usually reach the highest levels around parturition [112]. In cattle, a large amount of apelin was found in colostrum as well as in processed milk [112]. In the bovine mammary gland, apelin and its mRNA significantly increased during gestation, lactation, and reached the highest levels around parturition. Moreover, a large amount of apelin $(14-93 \mathrm{pmol} / \mathrm{mL})$ has been noticed in the colostrum, and it has been detectable in commercial bovine milk [112]. Apelin secreted in milk might work to the advantage of neonates by helping them survive through the modulation of their immune responses [113].

Nutritional status can affect apelin in serum and a hypercaloric diet increases adipose tissue and plasma apelin concentrations [114,115]. Norvezh et al. [116] demonstrated that alteration in the secretion of apelin-36 in dairy cow during early lactation may represent an endocrine adaptation mechanism during this critical period of lactation. Bhat et al. [117] used milk proteome analysis technique to explore the bioactive components of bovine milk and identified apelin as a major regulator of immune system in Kashmiri cattle. Furthermore, apelin appears to have an almost similar anti-inflammatory role as that of cortisol during inflammatory conditions. Studying the presence of apelin receptors on bovine phagocytic cells and its capability in modulating their bactericidal activity during stressful conditions as reported in other species is also needed in bovines.

\section{Conclusion}

Stress in any form, external or internal, greatly influences the productivity and well-being of dairy animals. The HPA axis and SNS system coordinate with the phagocytes and maintain through the release of various hormones, as discussed in this review. However, what are the mechanisms whereby the phagocytes and stress hormones interact with each other and what are the critical limits of a particular hormone above which it is detrimental to the welfare of the dairy cows is poorly understood. Therefore, more scientific studies that elaborate the immune-modulating mechanisms of these hormones and their interplay with other physiological pathways may help to select strategies to uncouple immunity from production. Further, genetic selection of stress-resistant animals, optimum nutrition, and regular monitoring of animals' health during periods of critical stress may help to reduce stress in dairy animals.

\section{Authors' Contributions}

MNA and AKD have contributed equally to this review.

\section{Acknowledgments}

The authors are thankful to the Department of Biotechnology, Ministry of Science and Technology, India, for sanctioning the DBT project (BT/PR29298/ AAQ/1/735/2018 dated 01.03.2019). The first author is thankful to the Syrian University of Aleppo for giving permission to carry out his Ph.D. research in India.

\section{Competing Interests}

The authors declare that they have no competing interests.

\section{Publisher's Note}

Veterinary World remains neutral with regard to jurisdictional claims in published institutional affiliation.

\section{References}

1. Sundrum, A. (2015) Metabolic disorders in the transition period indicate that the dairy cows' ability to adapt is overstressed. Animals, 5(4): 978-1020.

2. Overton, T.R., McArt, J.A.A. and Nydam, D.V. (2017) A 100-year review: Metabolic health indicators and management of dairy cattle. J. Dairy Sci., 100(12): 10398-10417.

3. Gross, J.J. and Bruckmaier, R.M. (2019) Invited review: Metabolic challenges and adaptation during different functional stages of the mammary gland in dairy cows: Perspectives for sustainable milk production. J. Dairy Sci., 102(4): 2828-2843.

4. Safa, S., Kargar, S., Moghaddam, G.A., Ciliberti, M.G. and Caroprese, M. (2019) Heat stress abatement during the postpartum period: Effects on whole lactation milk yield, indicators of metabolic status, inflammatory cytokines, and biomarkers of the oxidative stress. J. Dairy Sci., 97(1): 122-132.

5. Dahl, G.E., Tao, S. and Laporta, J. (2020) Heat stress impacts immune status in cows across the life cycle. Front. Vet. Sci., 7: 116 .

6. Adamo, S.A. (2014) The effects of stress hormones on immune function may be vital for the adaptive reconfiguration of the immune system during fight-or-flight behavior. Integr. Comp. Biol., 54(3): 419-426.

7. Sordillo, L.M. (2016) Nutritional strategies to optimize dairy cattle immunity. J. Dairy Sci., 99(6): 4967-4982.

8. de Oliveira, S., Rosowski, E.E. and Huttenlocher, A. (2016) 
Neutrophil migration in infection and wound repair: Going forward in reverse. Nat. Rev. Immunol., 16(6): 378.

9. Selders, G.S., Fetz, A.E., Radic, M.Z. and Bowlin, G.L. (2017) An overview of the role of neutrophils in innate immunity, inflammation and host-biomaterial integration. Regen. Biomater., 4(1): 55-68.

10. Soehnlein, O., Steffens, S., Hidalgo, A. and Weber, C. (2017) Neutrophils as protagonists and targets in chronic inflammation. Nat. Rev. Immunol., 17(4): 248-261.

11. Bassel, L.L. and Caswell, J.L. (2018) Bovine neutrophils in health and disease. Cell Tissue Res., 371(3): 617-637.

12. Alhussien, M.N. and Dang, A.K. (2019) Potential roles of neutrophils in maintaining the health and productivity of dairy cows during various physiological and physiopathological conditions: A review. Immunol. Res., 67(1): 21-38.

13. Vikhanski, L. (2016) Immunity: How Elie Metchnikoff Changed the Course of Modern Medicine. Chicago Review Press, United States.

14. Alhussien, M.N. and Dang, A.K. (2017) Integrated effect of seasons and lactation stages on the plasma inflammatory cytokines, function and receptor expression of milk neutrophils in Sahiwal (Bos Indicus) cows. Vet. Immunol. Immunopathol., 191: 14-21.

15. Alhussien, M.N. and Dang, A.K. (2018) Diurnal rhythm in the counts and types of milk somatic cells, neutrophil phagocytosis and plasma cortisol levels in Karan Fries cows during different seasons and parity. Biol. Rhythm Res., 49(2): 187-199.

16. Alhussien, M.N. and Dang, A.K. (2018) Impact of different seasons on the milk somatic and differential cell counts, milk cortisol and neutrophils functionality of three Indian native breeds of cattle. J. Therm. Biol., 78: 27-35.

17. Alhussien, M., Manjari, P., Sheikh, A.A., Seman, S.M., Reddi, S., Mohanty, A.K., Mukherjee, J. and Dang, A.K. (2016) Immunological attributes of blood and milk neutrophils isolated from crossbred cows during different physiological conditions. Czech J. Anim. Sci., 61(5): 223-231.

18. Jeon, S.J., Cunha, F., Ma, X., Martinez, N., Vieira-Neto, A., Daetz, R., Bicalho, R.C., Lima, S., Santos, J.E., Jeong, K.C. and Galvão, K.N. (2016) Uterine microbiota and immune parameters associated with fever in dairy cows with metritis. PLoS One, 11(11): e 0165740.

19. Alhussien, M., Kaur, M., Manjari, P., Kimothi, S.P., Mohanty, A.K. and Dang, A.K. (2015) A comparative study on the blood and milk cell counts of healthy, subclinical, and clinical mastitis Karan Fries cows. Vet. World., 8(5): 685-689.

20. Alhussien, M.N. and Dang, A.K. (2018) Milk somatic cells, factors influencing their release, future prospects, and practical utility in dairy animals: An overview. Vet. World, 11(5): 562-577.

21. Alhussien, M.N. and Dang, A.K. (2018) Pathogendependent modulation of milk neutrophils competence, plasma inflammatory cytokines and milk quality during intramammary infection of Sahiwal (Bos indicus) cows. Microb. Pathogl., 121: 131-138.

22. Panda, B.S., Mohapatra, S.K., Alhussien, M.N. and Dang, A.K. (2019) Amount of milk neutrophil percentage and associated CD molecular changes on the compositional and technological properties of milk. Open Biotechnol. J., 13(1): 129-136.

23. LeBlanc, S.J. (2020) Relationships between metabolism and neutrophil function in dairy cows in the peripartum period. Animal, 14(S1): 44-54

24. Khanam, S. (2017) Impact of stress on physiology of endocrine system and on immune system: A review. Int. $J$. Diabetes Endocrinol., 2(3): 40-42.

25. Sheldon, I.M., Cronin, J.G., Pospiech, M. and Turner, M.L. (2018) Symposium review: Mechanisms linking metabolic stress with innate immunity in the endometrium. J. Dairy Sci., 101(4): 3655-3664.

26. Savino, W. (2017) Prolactin: An immunomodulator in health and disease. Endocr. Immunol., 48: 69-75.

27. Berczi, I. and Nagy, E. (2019) Prolactin and other lactogenic hormones. In: Pituitary Function and Immunity. CRC Press, United States. p161-184.

28. Blalock, J.E. (1994) Shared ligands and receptors as a molecular mechanism for communication between the immune and neuroendocrine systems. Ann. N. Y. Acad. Sci., 741(1): 292-298

29. Csaba, G. (2014) Hormones in the immune system and their possible role. A critical review. Acta Microbiol. Immunol. Hung., 61(3): 241-260.

30. Bhatia, A., Sekhon, H.K. and Kaur, G. (2014) Sex hormones and immune dimorphism. Sci. World J., 2014: 159150.

31. Ong, Z. (2017) Characterizing Neutrophil Response to Estrogen During Mammary Involution, Doctoral Dissertation. Nanyang Technological University, Singapore.

32. Jurberg, A.D., Cotta-de-Almeida, V., Temerozo, J.R., Savino, W., Bou-Habib, D.C. and Riederer, I. (2018) Neuroendocrine control of macrophage development and function. Front. Immunol., 9: 1440.

33. Jara, E.L., Muñoz-Durango, N., Llanos, C., Fardella, C., González, P.A., Bueno, S.M., Kalergis, A.M. and Riedel, C.A. (2017) Modulating the function of the immune system by thyroid hormones and thyrotropin. Immunol. Lett., 184: 76-83.

34. Alhussien, M.N. and Dang, A.K. (2020) Sensitive and rapid lateral-flow assay for early detection of subclinical mammary infection in dairy cows. Sci. Rep., 10: 11161.

35. Paape, M.J., Bannerman, D.D., Zhao, X. and Lee, J.W. (2003) The bovine neutrophil: Structure and function in blood and milk. Vet. Res., 34(5): 597-627.

36. Ley, K., Laudanna, C., Cybulsky, M.I. and Nourshargh, S. (2007) Getting to the site of inflammation: The leukocyte adhesion cascade updated. Nat. Rev. Immunol., 7(9): 678

37. Conejeros, I., Gibson, A.J., Werling, D., Muñoz-Caro, T., Hermosilla, C., Taubert, A. and Burgos, R.A. (2015) Effect of the synthetic toll-like receptor ligands LPS, Pam 3 CSK 4, HKLM and FSL-1 in the function of bovine polymorphonuclear neutrophils. Dev. Comp. Immunol., 52(2): 215-225.

38. Villagra-Blanco, R., Silva, L.M., Muñoz-Caro, T., Yang, Z., Li, J., Gärtner, U., Taubert, A., Zhang, X. and Hermosilla, C. (2017) Bovine polymorphonuclear neutrophils cast neutrophil extracellular traps against the abortive Parasite Neospora caninum. Front. Immunol., 8: 606.

39. Mendez, J., Sun, D., Tuo, W. and Xiao, Z. (2018) Bovine neutrophils form extracellular traps in response to the gastrointestinal parasite Ostertagia ostertagi. Sci. Rep., 8(1): $1-12$.

40. Swain, D.K., Kushwah, M.S., Kaur, M., Patbandha, T.K., Mohanty, A.K. and Dang, A.K. (2014) Formation of NET, phagocytic activity, surface architecture, apoptosis and expression of toll-like receptors 2 and 4 (TLR2 and TLR4) in neutrophils of mastitic cows. Vet. Res. Commun., 38(3): 209-219.

41. Suriyasathaporn, W., Schukken, Y.H., Nielen, M. and Brand, A. (2000) Low somatic cell count: A risk factor for subsequent clinical mastitis in a dairy herd. J. Dairy Sci., 83(6): 1248-1255.

42. Dong, J., Li, J., Cui, L., Wang, Y., Lin, J., Qu, Y. and Wang, H. (2018) Cortisol modulates inflammatory responses in LPSstimulated RAW264. 7 cells via the NF-kB and MAPK pathways. BMC Vet. Res., 14(1): 30.

43. Roth, J.A. and Kaeberle, M.L. (1982) Effect of glucocorticoids on the bovine immune system. J. Am. Vet. Med. Assoc., 180(15): 894-901.

44. Grewal, S., Aggarwal, A. and Alhussien, M.N. (2019) Seasonal alterations in the expression of inflammatory cytokines and cortisol concentrations in periparturient Sahiwal cows. Biol. Rhythm Res., doi.org/10.1080/09291016.2019.1 670971 .

45. Ito, T., Aoki, N., Tsuchiya, A., Kaneko, S., Akiyama, K., Uetake, K. and Suzuki, K. (2017) Detection of stress 
hormone in the milk for animal welfare using QCM method. J. Sens., 2017: 1-7.

46. Brown, E.J. and Vosloo, A. (2017) The involvement of the hypothalamo-pituitary-adrenocortical axis in stress physiology and its significance in the assessment of animal welfare in cattle. Onderstepoort J. Vet. Res., 84(1): 1-9.

47. Pathak, R., Prasad, S., Kumaresan, A., Kaur, M., Manimaran, A. and Dang, A.K. (2015) Alterations in cortisol concentrations and expression of certain genes associated with neutrophil functions in cows developing retention of fetal membranes. Vet. Immunol. Immunopathol., 168(34): $164-168$.

48. Alhussien, M., Manjari, P., Mohammed, S., Sheikh, A.A., Reddi, S., Dixit, S. and Dang, A.K. (2016) Incidence of mastitis and activity of milk neutrophils in Tharparkar cows reared under semi-arid conditions. Trop. Anim. Health Prod., 48(6): 1291-1295.

49. Christison, G.I. and Johnson, H.D. (1972) Cortisol turnover in heat-stressed cows. J. Anim. Sci., 35(5): 1005-1010.

50. Lakhani, P., Alhussien, M.N., Lakhani, N., Jindal, R. and Nayyar, S. (2018) Seasonal variation in physiological responses, stress and metabolic-related hormones, and oxidative status of Murrah buffaloes. Biol. Rhythm Res., 49(6): 844-852.

51. Sordillo, L.M., Shafer-Weaver, K. and DeRosa, D. (1997) Immunobiology of the mammary gland. J. Dairy Sci., 80(8): 1851-1865.

52. Eicher, S.D., McMunn, K.A., Hammon, H.M. and Donkin, S.S. (2004) Toll-like receptors 2 and 4, and acute phase cytokine gene expression in dexamethasone and growth hormone treated dairy calves. Vet. Immunol. Immunopathol., 98(3): 115-125.

53. Mukherjee, J., Mallick, S., Chaudhury, M., Prakash, B.S. and Dang, A.K. (2015) Infradian rhythmicity in milk leukocyte activity together with plasma cortisol and prolactin levels throughout the lactation period in high-yielding crossbred cows. Biol. Rhythm Res., 46(6): 909-917.

54. Cui, L., Wang, Y., Wang, H., Dong, J., Li, Z., Li, J., Qian, C. and Li, J. (2020) Different effects of cortisol on pro-inflammatory gene expressions in LPS-, heat-killed E. coli-, or live E. coli-stimulated bovine endometrial epithelial cells. BMC Vet. Res., 16(1): 1-8.

55. Cui, L., Zheng, Y., Wang, H., Dong, J., Li, J., Song, Q., Qian, C. and Li, J. (2020) Cortisol inhibits the Escherichia coli-induced endometrial inflammatory response through $\mathrm{NF}-\kappa \mathrm{B}$ and MAPK pathways in postpartum goats. Anim. Reprod. Sci., 215: 106333.

56. Vannucchi, C.I., Silva, L.G., Lúcio, C.F. and Veiga, G.A. (2019) Oxidative stress and acid-base balance during the transition period of neonatal Holstein calves submitted to different calving times and obstetric assistance. J. Dairy Sci., 102(2): 1542-1550.

57. O'Neill, H.A. (2019) A review on the involvement of catecholamines in animal behaviour. S. Afr. J. Anim. Sci., 49(1): 1-8.

58. Bagath, M., Krishnan, G., Devaraj, C., Rashamol, V.P., Pragna, P., Lees, A.M. and Sejian, V. (2019) The impact of heat stress on the immune system in dairy cattle: A review. Res. Vet. Sci., 126: 94-102.

59. Reiske, L., Schmucker, S., Steuber, J. and Stefanski, V. (2019) Glucocorticoids and catecholamines affect in vitro functionality of porcine blood immune cells. Animals, 9(8): 545.

60. LaBranche, T.P., Ehrich, M.F. and Eyre, P. (2010) Characterization of bovine neutrophil $\beta 2$-adrenergic receptor function. J. Vet. Pharmacol. Ther., 33(4): 323-331.

61. Diez-Fraile, A., Meyer, E., Massart-Leën, A.M. and Burvenich, C. (2000) Effect of isoproterenol and dexamethasone on the lipopolysaccharide-induced expression of $\mathrm{CD} 11 \mathrm{~b}$ on bovine neutrophils. Vet. Immunol. Immunopathol., 76(1): 151-156.

62. Lyte, M. (2014) The effect of stress on microbial growth. Anim. Health Res. Rev., 15(2): 172-174.
63. Bacou, E., Haurogné, K., Allard, M., Mignot, G., Bach, J.M., Hervé, J. and Lieubeau, B. (2017) $\beta 2$-adrenoreceptor stimulation dampens the LPS-induced M1 polarization in pig macrophages. Dev. Comp. Immunol., 76: 169-176.

64. Margaryan, S., Hyusyan, A., Martirosyan, A., Sargsian, S. and Manukyan, G. (2017) Differential modulation of innate immune response by epinephrine and estradiol. Horm. Mol. Biol. Clin. Investig., 30(3): 0046.

65. Conlon, P.D., Ogunbiyi, P.O., Black, W.D. and Eyre, P. (1988) $\beta$-Adrenergic receptor function and oxygen radical production in bovine pulmonary alveolar macrophages. Can. J. Physiol. Pharmacol., 66(12): 1538-1541.

66. Currie, K.P., Zhou, Z. and Fox, A.P. (2000) Evidence for paracrine signaling between macrophages and bovine adrenal chromaffin cell Ca2+ channels. J. Neurophysiol., 83(1): 280-287.

67. Elenkov, I.J. and Chrousos, G.P. (1999) Stress hormones, Th1/Th2 patterns, pro/anti-inflammatory cytokines and susceptibility to disease. Trends Endrocrinol. Metab., 10(9): 359-368.

68. Sapolsky, R.M., Romero, L.M. and Munck, A.U. (2000) How do glucocorticoids influence stress responses? Integrating permissive, suppressive, stimulatory, and preparative actions. Endocr. Rev., 21(1): 55-89.

69. Vangroenweghe, F., Lamote, I. and Burvenich, C. (2005) Physiology of the periparturient period and its relation to severity of clinical mastitis. Domest. Anim. Endocrinol., 29(2): 283-293.

70. Lacasse, P., Zhao, X., Vanacker, N. and Boutinaud, M. (2019) Inhibition of prolactin as a management tool in dairy husbandry. Animal, 13(S1): 35-41.

71. Díaz, L., Muñoz, M.D., González, L., Lira-Albarrán, S., Larrea, F. and Méndez, I. (2013) Prolactin in the immune system. In: Nagy, G.M. and Toth, B.E., editors. Obstetrics and Gynecology. Prolactin, Boston.

72. Tang, M.W., Garcia, S., Fernandez, B.M. and Gerlag, D.M. (2017) Rheumatoid arthritis and psoriatic arthritis synovial fluid stimulates prolactin production by macrophages. The crosstalk of hormones and the immune system in rheumatoid arthritis. J. Leukoc. Biol., 102(3): 897-904.

73. Boutet, P., Sulon, J., Closset, R., Detilleux, J., Beckers, J.F., Bureau, F. and Lekeux, P. (2007) Prolactin-induced activation of nuclear factor $\mathrm{\kappa B}$ in bovine mammary epithelial cells: Role in chronic mastitis. J. Dairy Sci., 90(1): 155-164.

74. Ortega, E., Forner, M.A. and Barriga, C. (1996) Effect of prolactin on the in vitro phagocytic capacity of macrophages. Comp. Immunol. Microbiol. Infect. Dis., 19(2): 139-146.

75. Feola, R.P., Collins, M.T. and Czuprynski, C.J. (1999) Hormonal modulation of phagocytosis and intracellular growth of Mycobacterium aviumss. Paratuberculosis in bovine peripheral blood monocytes. Microb. Pathogl., 26(1): 1-11.

76. Gutiérrez-Barroso, A., Anaya-López, J.L., Lara-Zárate, L., Loeza-Lara, P.D., López-Meza, J.E. and Ochoa-Zarzosa, A. (2008) Prolactin modulates the expression of inflammatory response genes and stimulates the internalization of Staphylococcus aureus in bovine mammary epithelial cells. Vet. Immunol. Immunopathol., 121(1-2): 113-22.

77. Auchtung, T.L., Kendall, P.E., Salak-Johnson, J.L., McFadden, T.B. and Dahl, G.E. (2003) Photoperiod and bromocriptine treatment effects on expression of prolactin receptor mRNA in bovine liver, mammary gland and peripheral blood lymphocytes. J. Endocrinol., 179(3): 347-356.

78. Auchtung, T.L., Salak-Johnson, J.L., Morin, D.E., Mallard, C.C. and Dahl, G.E. (2004) Effects of photoperiod during the dry period on cellular immune function of dairy cows. J. Dairy Sci., 87(11): 3683-3689.

79. Vanacker, N., Ollier, S., Beaudoin, F., Blouin, R. and Lacasse, P. (2017) Effect of inhibiting the lactogenic signal at calving on milk production and metabolic and immune perturbations in dairy cows. J. Dairy Sci., 100(7): 
$5782-5791$.

80. Meazza, C., Pagani, S., Travaglino, P. and Bozzola, M. (2004) Effect of growth hormone (GH) on the immune system. Pediatr. Endocrinol. Rev., 1(3): 490-495.

81. Weigent, D.A. (2013) Lymphocyte GH-axis hormones in immunity. Cell. Immunol., 285(1-2): 118-132.

82. Silva, P.R.B., Nelson, C.D., Driver, J.P., Thatcher, W.W. and Chebel, R.C. (2017) Effect of recombinant bovine somatotropin on leukocyte mRNA expression for genes related to cell energy metabolism, cytokine production, phagocytosis, oxidative burst, and adaptive immunity. J. Dairy Sci., 100(10): 8471-8483.

83. Elvinger, F., Hansen, P.J., Head, H.H. and Natzke, R.P. (1991) Actions of bovine somatotropin on polymorphonuclear leukocytes and lymphocytes in cattle. J. Dairy Sci., 74(7): 2145-2152.

84. Massart-Leën, A.M., Burvenich, C., Heyneman, R., Roets, E. and Vandeputte-Van Messom, G. (1990) Leukocyte Function in Cows After Parturition: Involvement of Somatotropin. Vol. 126. $15^{\text {th }}$ Conference of European Comparative Endocrinology, Leuven, Belgium.

85. Mehrzad, J., Dosogne, H., Vangroenweghe, F. and Burvenich, C. (2002) Effect of bovine somatotropin (bST) on bactericidal activity of bovine neutrophil. Biotechnol. Agron. Soc. Environ., 6: 15.

86. Hoeben, D., Burvenich, C., Eppard, P.J. and Hard, D.L. (1999) Effect of recombinant bovine somatotropin on milk production and composition of cows with Streptococcus uberis mastitis. J. Dairy Sci., 82(8): 1671-1683.

87. Hammon, D.S., Evjen, I.M., Dhiman, T.R., Goff, J.P. and Walters, J.L. (2006) Neutrophil function and energy status in Holstein cows with uterine health disorders. Vet. Immunol. Immunopathol., 113(1): 21-29.

88. Silva, P.R.B., Machado, K.S., Da Silva, D.L., Moraes, J.G.N., Keisler, D.H. and Chebel, R.C. (2015) Effects of recombinant bovine somatotropin during the periparturient period on innate and adaptive immune responses, systemic inflammation, and metabolism of dairy cows. $J$. Dairy Sci., 98(7): 4449-4464.

89. Gulay, M.S., Liboni, M., Hayen, M.J. and Head, H.H. (2007) Supplementing Holstein cows with low doses of bovine somatotropin prepartum and postpartum reduces calving-related diseases. J. Dairy Sci., 90(12): 5439-5445.

90. Silva, P.R.B., Soares, H.F., Braz, W.D., Bombardelli, G.D., Clapper, J.A., Keisler, D.H. and Chebel, R.C. (2017) Effects of treatment of periparturient dairy cows with recombinant bovine somatotropin on health and productive and reproductive parameters. J. Dairy Sci., 100(4): 3126-3142.

91. Jeschke, M.G., Barrow, R.E. and Herndon, D.N. (2000) Recombinant human growth hormone treatment in pediatric burn patients and its role during the hepatic acute phase response. Crit. Care Med., 28(5): 1578-1584.

92. Akdis, C.A. and Blaser, K. (2003) Histamine in the immune regulation of allergic inflammation. J. Allergy Clin. Immunol., 112(1): 15-22.

93. Smuda, C., Wechsler, J.B. and Bryce, P.J. (2011) TLRinduced activation of neutrophils promotes histamine production via a PI3 kinase dependent mechanism. Immunol. Lett., 141(1): 102-108.

94. Cíz, M. and Lojek, A. (2013) Modulation of neutrophil oxidative burst via histamine receptors. Br. J. Pharmacol., 170(1): 17-22.

95. Zampeli, E. and Tiligada, E. (2009) The role of histamine $\mathrm{H} 4$ receptor in immune and inflammatory disorders. $\mathrm{Br} . \mathrm{J}$. Pharmacol., 157(1): 24-33.

96. Benbarek, H., Mouithys-Mickalad, A., Deby-Dupont, G., Deby, C., Grülke, S., Nemmar, A., Lamy, M. and Serteyn, D. (1999) High concentrations of histamine stimulate equine polymorphonuclear neutrophils to produce reactive oxygen species. Inflamm. Res., 48(11): 594-601.

97. Anderson, G.A., Stott, J.L. and Osburn, B.I. (1987) Identification of histamine-receptor leukocytes in the bovine. Vet. Res. Commun., 11(1): 77-82.

98. Phillips, T.R., Yang, W.C. and Schultz, R.D. (1987) In vitro effects of prostaglandin E1, prostaglandin E2, indomethacin, histamine, and tuftsin on chemiluminescence response of bovine polymorphonuclear leukocytes. Vet. Immunol. Immunopathol., 14(3): 233-244.

99. Inokuma, H., Kerlin, R.L., Kemp, D.H. and Willadsen, P. (1994) Histamine receptors on bovine peripheral blood lymphocytes. J. Vet. Med. Sci., 56(1): 45-49.

100. Szelag, A., Merwid-Lad, A. and Trocha, M. (2002) Histamine receptors in the female reproductive system. Part II. The role of histamine in the placenta, histamine receptors and the uterus contractility. Ginekol. Pol., 73(7): 636-644.

101. Willets, J.M., Taylor, A.H., Shaw, H., Konje, J.C. and Challiss, R.J. (2008) Selective regulation of H1 histamine receptor signaling by $\mathrm{G}$ protein-coupled receptor kinase 2 in uterine smooth muscle cells. Mol. Endocrinol., 22(8): 1893-1907.

102. Matta, S., Garg, S.K., Shah, M.A., Pant, H.C. and Sabir, M. (2001) Concentrations of histamine and 5-hydroxytryptamine in certain reproductive tissues of buffaloes (Bubalus bubalis). Indian J. Anim. Sci., 71(3): 248-250.

103. Bytautiene, E., Vedernikov, Y.P., Saade, G.R., Romero, R. and Garfield, R.E. (2002) Endogenous mast cell degranulation modulates cervical contractility in the guinea pig. $\mathrm{Am}$. J. Obstet. Gynecol., 186(3): 438-445.

104. Sharma, A., Choudhury, S., Nakade, U.P., Yadav, R.S. and Garg, S.K. (2014) Calcium influx and release mechanism (s) in histamine-induced myometrial contraction in buffaloes. Anim. Reprod. Sci., 146(3-4): 157-164.

105. Wang, G.Q., Hou, J.L., Huang, H.Y. and Yuan, C.W. (2016) Role of mast cells in cow metritis. J. Vet. Res., 60(2): 177-180.

106. Sun, X., Yuan, X., Chen, L., Wang, T., Wang, Z., Sun, G., Li, X., Li, X. and Liu, G. (2017) Histamine induces bovine rumen epithelial cell inflammatory response via NF- $\mathrm{BB}$ pathway. Cell Physiol. Biochem., 42(3): 1109-1119.

107. Chang, G., Wang, L., Ma, N., Zhang, W., Zhang, H., Dai, H. and Shen, X. (2018) Histamine activates inflammatory response and depresses casein synthesis in mammary gland of dairy cows during SARA. BMC Vet. Res., 14(1): 168.

108. Kawamata, Y., Habata, Y., Fukusumi, S., Hosoya, M., Fujii, R., Hinuma, S., Nishizawa, N., Kitada, C., Onda, H., Nishimura, O. and Fujino, M. (2001) Molecular properties of apelin: Tissue distribution and receptor binding. $B B A$ Mol. Cell Res., 1538(2-3): 162-171.

109. Kurowska, P., Barbe, A., Różycka, M., Chmielińska, J., Dupont, J. and Rak, A. (2018) Apelin in reproductive physiology and pathology of different species: A critical review. Int. J. Endocrinol., 2018: 9170480.

110. Newson, M.J.F., Pope, G.R., Roberts, E.M., Lolait, S.J. and O'Carroll, A.M. (2013) Stress-dependent and gender-specific neuroregulatory roles of the apelin receptor in the hypothalamic-pituitary-adrenal axis response to acute stress. J. Endocrinol., 216(1): 99-109.

111. Kagiyama, S., Fukuhara, M., Matsumura, K., Lin, Y., Fujii, K. and Iida, M. (2005) Central and peripheral cardiovascular actions of apelin in conscious rats. Regul. Pept., 125(1-3): 55-59.

112. Habata, Y., Fujii, R., Hosoya, M., Fukusumi, S., Kawamata, Y., Hinuma, S., Kitada, C., Nishizawa, N., Murosaki, S., Kurokawa, T. and Onda, H. (1999) Apelin, the natural ligand of the orphan receptor APJ, is abundantly secreted in the colostrum. BBA Mol. Cell Res., 1452(1): 25-35.

113. Aydin, S. (2013) Presence of adropin, nesfatin-1, apelin-12, ghrelins and salusins peptides in the milk, cheese whey and plasma of dairy cows. Peptides, 43: 83-87.

114. Ranjbar, N.K., Nazifi, S.A.E., Tabandeh, M.R. and Ansari, M.L. (2018) Effect of L-carnitine supplementation on apelin and apelin receptor (apj) expression in cardiac muscle of obese diabetic rats. Cell J., 20(3): 427-434. 
115. Nazari, M., Moghimipour, E. and Tabandeh, M.R. (2017) Betaine down-regulates apelin gene expression in cardiac and adipose tissues of insulin-resistant diabetic rats fed by high-calorie diet. Int. J. Pept. Res. Ther., 23(2): 181-190.

116. Norvezh, F., Jalali, M.R., Tabandeh, M.R., Hajikolaei, M.R.H. and Gooraninejad, S. (2019) Serum apelin-36 alteration in late pregnancy and early lactation of dairy cows and its association with negative energy balance markers. Res. Vet. Sci., 125: 285-289.

117. Bhat, S.A., Ahmad, S.M., Ibeagha-Awemu, E.M., Mobashir, M., Dar, M.A., Mumtaz, P.T., Shah, R.A., Dar, T.A., Shabir, N., Bhat, H.F. and Ganai, N.A. (2020) Comparative milk proteome analysis of Kashmiri and Jersey cattle identifies differential expression of key proteins involved in immune system regulation and milk quality. BMC Genomics, 21(1): 1-10.

$* * * * * * * *$ 